\title{
ONLY EMPIRICISM IS COMPATIBLE WITH BEHAVIOR ANALYSIS: A Response to the Socialism and Behaviorism Debate
}

\author{
Bobby Newman \\ Department of Psychology \\ Queens College, CUNY
}

\begin{abstract}
The question of which political system is most compatible with applied behavior analysis is examined, a response to the "Socialism and Behaviorism" debate from two recent issues of Behavior Analysis and Social Action. Various areas of social policy (the environment, overpopulation, industry and welfare) are examined. It is concluded that no system other than pragmatic empiricism is compatible with behavior analysis, or is likely to lead to successful solutions across all these diverse areas.
\end{abstract}

November 12, 1989 was a big day for the pro-choice forces in the abortion struggle. A few hundred thousand people poured into the U.S. capital to proclaim their (in my opinion, righteous) support for a woman's right to choose what should happen to her body. While walking in the crowd I came across a table with a huge banner proclaiming "We're pro-choice everything!" "There's a tolerant bunch", I thought. As I approached I recognized the literature of the Libertarian political party. Just to the right of this table was another display. The literature on this table was also unmistakable. The Young Socialists were out in force, ready to stand up against the oppressive government's attempts to limit women's reproductive freedom.

There are libertarians who are anti-abortion, claiming that individual rights begin at conception. There are also socialists who believe that "cradle to grave" should actually extend from "conception to grave". Regardless, however, the majority opinion in both camps seems to be pro-choice. I thought it interesting, that people with such disparate political ideologies could find an issue upon which they agreed, at least in the basic idea if not in the details and justifications (e.g. how abortions should be funded, why anti-abortion laws are unacceptable). The debates between libertarians (who are really radical capitalists--Rothbard, 1978) and socialists are fascinating and voluminous, each attempting to prove their system the

\section{AUTHOR'S NOTE:}

I would like to thank Leo Newman and Dr. Nancy S. Hemmes for editorial and conceptual assistance. Correspondence concerning this article should be addressed to the author at the Department of Psychology, Queens College, CUNY, Flushing, NY 11367 


\section{NEWMAN}

superior through the use of historical and current examples, as well as appeals to ideology. Ideology is defined here as behavior, in this case verbal behavior, which conforms to a set of rules or precepts considered correct and unchanging. Because the rules are considered correct and unchanging, they do not allow for the testing of interventions central to applied behavior analysis and are therefore undesirable.

In the "Socialism and Behaviorism" debate (Behavior Analysis and Social Action, 6(2), p. 16-32; 7, p. 23-34) Richard F. Rakos, Joseph E. Morrow, and Jerome D. Ulman examine socialism and capitalism, and attempt to explain from a behavioral perspective why one system or the other is to be preferred. In so doing, the authors forgot one of the most basic tenets of behavior analysis--treat each problem as a separate entity and do not assume that what is effective in one setting will necessarily prove effective in another. If behavior analysis is to give us any insight into designing social policy, then we must carefully define our problems and avoid making sweeping statements. Each problem area must be treated individually. This does not mean that the wider context must be ignored (see Wahler and Fox's (1981) analysis of setting events in applied behavior analysis). What it does mean is that it should not be assumed that any global policy (including socialism or capitalism) is likely to function as a panacea. To cavalierly implement a global intervention without an examination of the contingencies affecting the behaviors of interest is not consistent with the "analysis" in applied behavior analysis. In the following passages I will examine a few areas of social policy in an attempt to demonstrate that no political stance other than a willingness to analyze the contingencies of each individual problem area is likely to lead to successful solutions. This empiricist stance conforms closely to the point of view known as "pragmatism" (Ulman, personal communication, 1990). Although the term "pragmatism" has been used in many ways, the term as used here is defined as a belief that policies should not be "...judged by their intrinsic righteousness or truth but, instead, should be evaluated in terms of their consequences." (Kendler, 1987, p. 129). More than any other guiding philosophy, this idea seems to be compatible with the standard behavioral practice of setting a behavioral goal expected to maximize future reinforcement, and evaluating interventions in terms of whether or not the behavioral goals were reached (and not in terms of any other conception of "truthfulness"). It could be argued that this pragmatic viewpoint also constitutes an ideology and is, for the reason mentioned above, therefore undesirable. If pragmatic empiricism is an ideology, it is one only in the broadest sense (the unchanging rule being that all policies must be open to question). Because of its adaptability, and its failure to block the testing of assertions (and actually demanding those tests), this guiding philosophy would seem to be compatible with the practice of applied behavior analysis. 


\section{ONLY EMPIRICISM}

\section{THE ENVIRONMENT}

One of the most inspiring endings to a novel that I've ever read was that of Anthem, Ayn Rand's troubling vision of a socialist world. At the end of the novel, protagonist Equality 7-2521 (then renamed Prometheus) reclaims the individuality lost to humanity when the collectivist revolution occurred. $\mathrm{He}$ also begins to recreate the Genesis myth, reclaiming the dominion of humanity over the world and its resources and creatures.

The results of human dominion over the Earth and its creatures should not be news to anyone. Extinctions of animal and plant species have been widespread (e.g. Mowat, 1986), and continue at an accelerating pace. The rain forests of the world are disappearing, leading to further extinctions and possibly global changes in climate (Caufield, 1984; Forsyth \& Miyata, 1984). The hole in the ozone layer, resource shortages and toxic waste are just a few examples of the result of indiscriminate exploitation of nature by humanity, and a lack of concern with environmental impact. The libertarian position on the environment, that no government has the right to interfere with the individual's right to use available resources (as described in Agras, Jacob \& Lebedeck, 1980, for example), is thus probably not acceptable in the long run to anyone concerned with the continuing quality of life on the planet.

The indiscriminate abuse of resources by humanity (e.g. Milleman, 1986), and our failure to respond to the results of this abuse, are predicted by both Herrnstein's hyperbola and by the "choice behavior" literature. Briefly stated, Herrnstein's hyperbola states that reinforcers must be considered relative to the density of all other reinforcers in the environment in order to predict effects (McDowell, 1982). Rachlin and Green's (1972) study of self-control suggested that organisms will prefer immediate reinforcers to temporally distant reinforcers, even if the temporally distant reinforcer is of greater magnitude than the immediate reinforcer (in accordance with the dimensions specified by the matching law). Similarly, Deluty (1978) found that temporally distant aversive stimuli will be preferred to more immediate aversive stimuli, even if the temporally distant aversive stimulus is of greater magnitude than the more immediate aversive stimuli. For the question of environmental preservation, the key point relating these studies is that the immediate reinforcement of consuming resources and disposing of the waste is too powerful to be countered by the temporally distant punishing contingencies (and many still consider this stimulus to be infinitely delayed) of an uninhabitable planet (Skinner, 1989).

It may be that the recent concern with the environment (e.g. "Earth Day" 1990) will lead to contingencies that favor environmental preservation. The power of consumers, for example, to favor companies that are environmentally responsible may alleviate some of the damage done by industry in the wealthier nations. This is unlikely to make a significant impact on the global scale, however. How long this 


\section{NEWMAN}

concern will be in the public eye remains to be seen. How well industry may be able to hide its destructive practices is also unknown. Finally, in many countries there may be no incentive for industry to change its practices, and in the poorer nations there may be no choice but to continue the environmentally destructive practices (e.g. deforestation for farm land for growing populations). Some form of government control on resource exploitation (e.g. the proposed multi-national ban on resource exploitation in the Antarctic) is thus probably required if we are to prevent entering a time in which the aversive stimulation of an uninhabitable planet becomes more immediate and competitive with the reinforcement of consumption.

\section{OVERPOPULATION}

It was Parson Thomas Malthus who popularized the point that human population increases at a far faster rate than resources can be increased. The Club of Rome came to a confirmatory conclusion, stating that there are real limits to the growth of human population and resource consumption. Despite the dangers of overpopulation, and the problems which are inherent in a society that overpopulates, the trend of overpopulation continues in many countries in the world (Fornos, 1987; Mumford, 1984). We can probably regard this trend as similar in nature to the trend of environmental destruction. The short-term reinforcers of having children (for the individual, government, church or some other special interest group), be they social, economic or intrinsic, are too powerful for the long-range punishers to compete.

As with the environmental crisis, this trend cannot continue forever. Eventually there will be an "evening up" of the contingencies. The key question comes down to the nature of the control mechanism involved. Should child-bearing be limited by society (a concept most would probably dislike), or should the crisis be allowed to reach a stage such that the aversive consequences of child-bearing become immediate (a concept most would probably like even less)? Rather than trusting political philosophies (and both the socialists and the libertarians believe that their systems solve this problem), we would be better off analyzing the contingencies of this problematic area (e.g. Cone \& Hayes, 1984) and designing social policy accordingly. It is my impression that the evidence favors the need for state intervention. This need not only take the form of limits on the number of children a given family can have (e.g. the Chinese effort). As pointed out by Fornos (1990), a great many women, particularly in the developing countries, would like to cease having children but lack the education or resources to realize this wish. (Adding to this problem, the United States government, pressured by "pro-life" forces, has cut its aid for voluntary family planning in developing countries). Rather than state intervention functioning to set guidelines for behavior, this area may also require state intervention which makes adaptive behavior possible. 


\section{ONLY EMPIRICISM}

\section{INDUSTRY}

What it is that causes people to be truly productive was one of the main points of contention for Ulman (1988) and Rakos (1988a). Reading their articles, I was reminded of the contrast between Upton Sinclair's scathing view of capitalism, The Jungle, and the previously mentioned and equally scathing view of socialism, Anthem. While neither Ulman nor Rakos went as far as the novelists did in advocating their system and pointing out weaknesses in the opposing system, both looked at the same ideas and phenomena and came to radically different conclusions.

According to Rakos, the capitalist system is the superior. He feels that the contingent relationship between work and obtaining material and subsequent social reinforcers is in keeping with a view of human nature as described by behavior analysis. Ulman takes issue with this conception (a rather bourgeois conception, in Ulman's view), questioning the level of Rakos' analysis and the use of the term "human nature". Rakos (1988a, p. 16) himself acknowledges that "human nature" is an explanatory fiction, but nonetheless is willing to accept capitalism as consistent with an "operationalized conception of human nature" (p. 20). I think the evidence supports Rakos' view that there must be a contingent relationship between work and reinforcement, but I also agree with Ulman (p. 27) that the behavior we might attribute to "human nature", operationalized or not, is better conceptualized as being selected by its consequences. To say that one social system or another takes better advantage of this relationship is one thing. To say that one system is more consistent with human nature is quite another.

The poor state of the economies of the socialist countries would seem to suggest that socialism is not a very effective system with regards to industry, possibly for the reasons cited by Rakos. Ulman has suggested that the economic success of Cuba over the past four years, since the beginning of the "rectification" program, proves that socialism can work. Whether we agree with UIman or with Rakos, who suggests that Cuba's success may be due to Soviet subsidies, I think we can agree that it is still too soon to tell whether Cuba's success is real or illusory.

The success of capitalism, and its weakness, is due to its competitive nature. Nothing is assured, and successful business and industry behaviors are selected by their consequences. The recent Savings and Loan fiasco aside, such consequences as profits and continued existence generally select industry behaviors. The problem inherent in this system was touched upon by Morrow (1988). He mentions that the distribution of available reinforcers under capitalism is positively skewed, to say the least. In a competitive situation there must always be winners and losers. The problem with pure capitalism is that losers lose big, and there are no resources for those who lose to fall back upon. This in turn has serious consequences for the nation as a whole (hence the New Deal of Roosevelt). 


\section{NEWMAN}

\section{WELFARE}

This last point is questioned by libertarians, who regard socialism as "...envy writ large, and elevated to a moral ideal. It brands the most productive as criminals and makes heroes of those who have difficulty achieving anything at all" (Sheaffer, 1989, p. 20). While it is tempting to simply write this off as "haves" who see no reason to give to the "have nots", there is a serious behavioral notion in question.

Among libertarians there is a theory known as the "quick as hell" theory. The quick as hell theory states that as soon as welfare and unemployment benefits are no longer available, then everyone who doesn't have a job will find one, quick as hell. The obvious implication is that people who do not work and instead receive some sort of government relief are lazy or unmotivated, or, more charitably, have figured the system out. (Although perhaps this radical version of capitalist thinking is not widespread, the general idea is well-grounded in popular thought, hence the success of Ronald Reagan's "people on welfare driving cadillacs" rhetoric). Attributing behavior to something inherent in the individual is contrary to what behavior analysis has taught us about human conduct. If we must blame, we should blame the contingencies which have led to this "inactive" behavior (Holland, 1978), including the welfare system itself, which punishes independent earning with lessened benefits.

To behaviorists, the crucial question of welfare comes down to whether or not inactivity and increases in family size are reinforced by welfare benefits. The answer is, of course, that in some cases it does and in other cases it does not. The truth is that most people on welfare do not become life-long recipients. It is my impression, formed from my work as a crime victims counselor in New York City's social services network, that most people on welfare do not particularly enjoy the experience and use welfare only as a temporary resource. On the other hand, to anyone who went through public school in any large city in the United States, it was no news to meet a third generation welfare recipient or a teenage woman who had had a child so as to begin receiving welfare benefits as a separate family unit. It is the double-edged nature of the evidence that so confounds the question.

Pure capitalism, and vacuum behaviorism, would say eliminate welfare because it's counter-productive for the recipient. It's always poor strategy to provide noncontingent reinforcement and expect behavior to change only in desired directions. We are not living in a vacuum, however. In my work, for example, I often come across battered women who wish to leave their abusive husbands. Many have no financial resource for themselves and (usually) for their children. To eliminate welfare is to force them to stay in the abusive situation, or to be thrown out on the street. Economic disasters are also faced by families in which the main provider becomes seriously ill, or in geographic areas where a large source of employment (e.g., a mill or factory) closes. For just such emergencies, at least temporary welfare must be available. This is not only a humanitarian argument, 


\section{ONLY EMPIRICISM}

it is a practical one as well. Without the means to obtain material reinforcers, crime becomes more probable (the counter-control that often follows aversive conditions--Sidman, 1989). Further, a country in which the population cannot afford the products of its industry will face economic hardship unless it has a large export over import surplus (which the United States does not).

As a provision of the federal Family Support Act of 1988, many states are now trying to eliminate the noncontingent nature of welfare, forcing recipients to accept jobs or education in return for their benefits ("workfare"). The results of these interventions will be quite interesting, and I'm optimistic. (Arguments aside about whether or not some people should be given what other people have to work long hours to obtain, in February of 1990 the City University of New York announced a study demonstrating that welfare recipients who receive a college education have a very high employment rate and leave the welfare rolls). I also don't doubt that a great many other problems will become apparent and require attention as a result (e.g. child care must be made available, serious remedial education will be required before many are ready to take jobs, and the problem described by Rakos--you can make benefits contingent on showing up for work, but getting people to be productive is quite another matter). Nonetheless, living on welfare is not a particularly pleasant experience. Perhaps if the productive behaviors of recipients are reinforced, the effects will generalize and some self-help behaviors will begin to be exhibited (as suggested by Miller \& Miller, 1970).

\section{CONCLUSION}

If any point at all is apparent, it is clear that neither pure capitalism nor pure socialism is likely to be helpful in all of the areas described above. Pure capitalism is acceptable only if one is willing to accept a situation of "every person for her/himself", and accept inevitable disaster for a large segment of the population and possibly for the greater society as well. If this is not acceptable, then some "socialist" interventions are required. It is my opinion that a measure of state control must be balanced along with exposure to naturally occurring contingencies. The state controls function so as to equalize the disparity between short-term reinforcers and long-term punishers. They also hopefully prevent problems which can rise from the behavior of following short-term reinforcers.

To this end, behavior analysts may design any social policy. Of course, the problem of how to get the designed policy implemented still exists. The fact that a practice achieves stated goals provides no guarantee that it will be appreciated or implemented (e.g., Watkins 1988). Geller (1989) has described an integration of applied behavior analysis and social marketing with regard to popularizing behavioral interventions aimed at environmentally relevant behaviors. His strategy involves appreciating the contingencies influencing, and designing interventions addressing, the various groups involved in the problem area (including government 


\section{NEWMAN}

officials). His strategy lends itself to a systematic effort regarding the political process, and may provide the route by which behavioral strategies will make their way into government policy.

We must, however, be willing to test the effectiveness of any proposed intervention and be willing to reject established policy, even if this action conflicts with political ideology. It is not an easy step to take, witness the disastrous seventy-six year old war on drugs (Marshall, 1988), but is essential if we are to keep our status as behavior analysts rather than political ideologues. A Comte-inspired "behaviorist" political party would consist of individuals who had tired of the promises of political philosophy and who instead trust empiricism as the path to designing policy. As Rakos (1988b) himself says, "...we must employ scientific analyses rather than political ones, since in the long run, a more equitable and just society will depend more on empiricism than on ideology." I would add that the empiricism must be more problem-specific than Rakos' general approach.

It might be suggested that this would be impossible, and that as soon as a behavior analyst moves into the social environment (s)he goes beyond the data and loses the non-ideological stance. I would disagree and cite the Los Horcones (1989) community as evidence. Policies there are attempted and, if they do not achieve their desired aims, are changed. The behavior analysts at Los Horcones are not going beyond their data, their data are derived from the policies they design. The behavior analysts are active members of the community, but can, because of their emphasis on empiricism, remain free of any other political ideology. This is the framework from which I make my suggestion of a non-ideological stance. The conclusions I drew above as to what type of policies in each problem area would be required are tentative, and open to test. If they proved to be ineffective or damaging, then they would be changed.

It should come as no surprise that no single political policy or philosophy which attempts to cross all areas can supply all the answers. We would never seriously suggest that all problems can be solved by the institution of a single intervention procedure (e.g., "overcorrection will solve all behavior problems"). By the same token, we should not suggest that any one political philosophy is likely to provide all the answers. Only by examining each problem area as its own subject matter will we be able to make a serious contribution to the design of public policy.

\section{REFTRENCES}

Agras, W.S., Jacob, R.G., \& Lebedeck, M. (1980). The California drought: A quasi-experimental analysis of social policy. Journal of Applied Behavior Analysis, 13, 561-570. http://dx.doi.org/10.1901/jaba.1980.13-561

Caufield, C. (1984). In the rainforest. Chicago: The University of Chicago Press.

Cone, J.D. \& Hayes, S.C. (1984). Environmental problems: Behavioral solutions. Monterey, CA: Brooks/Cole. 


\section{ONLY EMPIRICISM}

Deluty, M.Z. (1978). Self-control and impulsiveness involving aversive events. Journal of Experimental Psychology: Animal Behavior Processes, 4, 250-266. http://dx.doi.org/10.1037/0097-7403.4.3.250

Fornos, W. (1987). Gaining people, lasing ground: A blueprint for stabllizing world population. Ephrata, Pennsylvania: Science Press.

Fornos, W. (1990). Gaining people, losing ground. The Humanist, 50(3), 56.

Forsyth, A. \& Miyata, K (1984). Tropical nature, New York: Charles Scribner's Sons.

Geller, E.S. (1989). Applied behavior analysis and social marketing: An integration for environmental preservation. Joumal of Social Issues, 45(1), 17-36. http://dx.doi.org/10.1111/j.1540-4560.1989.tb01531.x

Holland, J.G. (1978). Behaviorism: Part of the problem or part of the solution? Journal of Applied Behavior Analysis, 11, 163-174. http://dx.doi.org/10.1901/jaba.1978.11-163

Kendler, H.H. (1987). Historical foundations of modern psychology. Chicago: The Dorsey Press.

Los Horcones (1989). Personalized government: A governmental system based on behavior analysis. Behavior Analysis and Social Action, 7, 42-47.

Marshall, E. (1988). Flying blind in the war on drugs. Sclence, 240, 1605-1607.http://dx.doi.org/10.1126/science.3381085

McDowell, J.J. (1982). The importance of Hermstein's mathematical statement of the law of effect for behavior therapy. American Psychologist, 37, 771.779. http://dx.doi.org/10.1037/0003-066X.37.7.771

Milleman, B. (1986). And two if by sea: Fighting the attack on America's coasts, Washington, D.C.: Coast Alliance, Inc.

Miller, L.K. \& Miller, O.L. (1970). Reinforcing self-help group activities of welfare recipients. Joumal of Applied Behavior Analysis, 3, 57-64. http://dx.doi.org/10.1901/jaba.1970.3-57

Morrow, J.E. (1988). Is socialism flawed? Behavior Analysis and Social Issues, 6(2), 23-24.

Mowat, F. (1986), Sea of slaughter. New York: Bantam Books.

Mumford, S.D. (1984). American democracy and the Vatican: Population growth and national security. Amherst, NY: The Humanist Press.

Rachlin, H., \& Green, L. (1972). Commitment, choice, and self-control. Joumal of the Experimental Analysis of Behavior, 17, 15-22. http://dx.doi.org/10.1901/jeab.1972.17-15

Rakos, R.F. (1988a). Capitalism, socialism, and behavioral theory. Behavior Analysis and Social Action, 6(2), 16-22.

Rakos, R.F. (1988b). Scientific analysis or political ideology? Behavior Analysis and Social Action, 6(2), 32.

Rakos, R.F. (1989). Socialism, behavioral theory, and the egalitarian society. Behavior Analysis and Social Action, 7, 23-29.

Rothbard, M.N. (1978). For a new liberty: The libertarian manifesto. New York: The Libertarian Review Foundation.

Sheaffer, R. (1989). Socialism is Incompatible with humanism. Free Inquiry, 9(4), 19-20.

Sidman, M. (1989). Coercion and it fallout. Boston, Mass: Authors Cooperative, Inc.

Skinner, B. F. (1989). Recent issues in the analysis of behavior. Toronto: Merrill Publishing.

Ulman, J.D. (1988). Just say no to commodity fetishism: A reply to Rakos. Behavior Analysis and Social Action, 6(2), 25-31. 


\section{NEWMAN}

Ulman, J.D. (1989). Beyond the carrot and the stick: A behavioral rejoinder to Rakos. Behavior Analysis and Social Action, 7, 30-34.

Wahler, R.G. \& Fox, J.J. (1981). Setting events in applied behavior analysis: Toward a conceptual and methodological expansion. Journal of Applied Behavior Analysis, 14, 327-338. http://dx.doi.org/10.1901/jaba. 1981.14-327

Watkins, C.L (1988). Project Follow Through: A story of the identification and neglect of effective instruction. Youth Policy, 10(7), 7-11. 